\title{
Public versus Private Drug Insurance and Outcomes of Patients Requiring Biologic Therapies for Inflammatory Bowel Disease
}

\author{
Amir Rumman, ${ }^{1}$ Roberto Candia, ${ }^{2,3}$ Justina J. Sam, ${ }^{4}$ Kenneth Croitoru, ${ }^{4,5}$ \\ Mark S. Silverberg, ${ }^{4,5}$ A. Hillary Steinhart, ${ }^{4,5}$ and Geoffrey C. Nguyen ${ }^{3,4,5}$ \\ ${ }^{1}$ Department of Medicine, University of Toronto, Toronto, ON, Canada \\ ${ }^{2}$ Departamento de Gastroenterología, Facultad de Medicina, Pontificia Universidad Católica de Chile, Santiago, Chile \\ ${ }^{3}$ Institute of Health Policy, Management and Evaluation, University of Toronto, Toronto, ON, Canada \\ ${ }^{4}$ Mount Sinai Hospital Centre for Inflammatory Bowel Disease, University of Toronto, Toronto, ON, Canada \\ ${ }^{5}$ Division of Gastroenterology, Department of Medicine, University of Toronto, Toronto, ON, Canada
}

Correspondence should be addressed to Geoffrey C. Nguyen; geoff.nguyen@utoronto.ca

Received 21 September 2016; Accepted 13 December 2016; Published 23 January 2017

Academic Editor: Mark Borgaonkar

Copyright (C) 2017 Amir Rumman et al. This is an open access article distributed under the Creative Commons Attribution License, which permits unrestricted use, distribution, and reproduction in any medium, provided the original work is properly cited.

\begin{abstract}
Background. Antitumor necrosis factor (anti-TNF) therapy is a highly effective but costly treatment for inflammatory bowel disease (IBD). Methods. We conducted a retrospective cohort study of IBD patients who were prescribed anti-TNF therapy (2007-2014) in Ontario. We assessed if the insurance type was a predictor of timely access to anti-TNF therapy and nonroutine health utilization (emergency department visits and hospitalizations). Results. There were 268 patients with IBD who were prescribed anti-TNF therapy. Public drug coverage was associated with longer median wait times to first dose than private one (56 versus 35 days, $P=0.002)$. After adjusting for confounders, publicly insured patients were less likely to receive timely access to anti-TNF therapy compared with those privately insured (adjusted hazard ratio, 0.66; 95\% CI: 0.45-0.95). After adjustment for demographic and clinical characteristics, publicly funded subjects were more than 2-fold more likely to require hospitalization (incidence rate ratio [IRR], 2.30; 95\% CI: 1.19-4.43) and ED visits (IRR 2.42; 95\% CI: 1.44-4.08) related to IBD. Conclusions. IBD patients in Ontario with public drug coverage experienced greater delays in access to anti-TNF therapy than privately insured patients and have a higher rate of hospitalizations and ED visits related to IBD.
\end{abstract}

\section{Introduction}

Crohn's disease (CD) and ulcerative colitis (UC) are two idiopathic inflammatory bowel diseases (IBD) characterized by chronic diarrhea, abdominal pain, and diminished quality of life [1,2]. A third of patients with $\mathrm{CD}$ and $12 \%$ of those with UC require surgery within 5 years after diagnosis [3]. Currently, antitumor necrosis factor agents are among the most effective medical therapies for inducing and maintaining remission and achieving mucosal healing for $\mathrm{CD}$ and $\mathrm{UC}[1,2$, $4-7]$. Though biologics have been conventionally indicated in individuals who are steroid-refractory or dependent and have failed immunomodulator therapy, there is growing evidence that biologic therapy may be more effective if given earlier in the course of disease $[8,9]$. Moreover, biologic therapy has been associated with reduced hospitalizations and surgery [10-12].

The major barrier for utilization of biologic therapy is its high cost. In Ontario, the exceptional access program (EAP) is administered by the Ministry of Health and Longterm Care and facilities access to biologic therapies for IBD patients that lack supplementary private drug coverage. The EAP reimbursement criteria for initial approval of infliximab or adalimumab for Crohn's disease and ulcerative colitis patients are shown in Table 1. For patients with private drug insurance, coverage criteria for initial approval of infliximab or adalimumab vary significantly based on the insurance provider.

Although both systems enable access to biologic therapy, many gastroenterologists in Ontario feel that the type of 
TABLE 1: Exceptional access program (EAP) reimbursement criteria for initial approval for use in Crohn's disease and ulcerative colitis patients. These criteria did not change during the study period.

\begin{tabular}{|c|c|}
\hline Reimbursement criteria & Covered drugs \\
\hline $\begin{array}{l}\text { Treatment of fistulising Crohn's disease in patients with actively draining perianal } \\
\text { disease or enterocutaneous fistula(e) that have recurred or persisted despite a } \\
\text { course of antibiotic therapy (ciprofloxacin and/or metronidazole) and } \\
\text { immunosuppressive therapy (azathioprine or 6-mercaptopurine). }\end{array}$ & $\begin{array}{l}\text { Infliximab } \\
\left(\text { Remicade }^{\circledR}\right) \\
\text { Adalimumab }^{\left(\text {Humira }^{\circledR}\right)}\end{array}$ \\
\hline $\begin{array}{l}\text { Treatment of moderate to severe (luminal) Crohn's disease in patients who have } \\
\text { (i) Harvey-Bradshaw Index (HBI) score } \geq 7 \text {, } \\
\text { (ii) failed to respond to conventional treatment with corticosteroids (prednisone } \\
40 \mathrm{mg} / \text { day or equivalent for at least two weeks) or dose cannot be tapered below } \\
\text { prednisone } 20 \mathrm{mg} / \text { day or equivalent, } \\
\text { (iii) failed to respond to an immunosuppressive agent (azathiopurine, } \\
\text { 6-mercaptopurine, methotrexate, or cyclosporine) tried for at least } 3 \text { months. }\end{array}$ & $\begin{array}{c}\text { Infliximab } \\
\left.\text { (Remicade }^{\circledR}\right) \\
\text { Adalimumab } \\
\left.\text { (Humira }^{\circledR}\right)\end{array}$ \\
\hline $\begin{array}{l}\text { Mild ulcerative colitis: } \\
\text { (i) Mayo score < } 6 \text {; } \\
\text { (ii) patients with mild disease will be considered on a case-by-case basis but } \\
\text { submission must include rationale for coverage. }\end{array}$ & $\begin{array}{c}\text { Infliximab } \\
\left(\text { Remicade }^{\circledR}\right)\end{array}$ \\
\hline $\begin{array}{l}\text { Moderate ulcerative colitis: } \\
\text { (i) Mayo score between } 6 \text { and } 10 \text { (inclusive), } \\
\text { (ii) endoscopic subscore of } 2 \text {, } \\
\text { (iii) failed } 2 \text { weeks of oral prednisone } 40 \mathrm{mg} / \text { day (or IV equivalent for at least } 1 \\
\text { week) and } 3 \text { months of azathioprine or } 6 \text {-mercaptopurine, or where the use of } \\
\text { immunosuppressants is contraindicated, } \\
\text { (iv) stabilized with } 2 \text { weeks of oral prednisone } \geq 40 \mathrm{mg} / \text { day (or IV equivalent for at } \\
\text { least } 1 \text { week) but the prednisone dose cannot be tapered despite } 3 \text { months of } \\
\text { azathioprine or } 6 \text {-mercaptopurine, or where the use of immunosuppressants is } \\
\text { contraindicated. }\end{array}$ & $\begin{array}{c}\text { Infliximab } \\
\left(\text { Remicade }^{\circledR}\right)\end{array}$ \\
\hline $\begin{array}{l}\text { Severe ulcerative colitis: } \\
\text { (i) Mayo score between }>10 \text {, } \\
\text { (ii) endoscopic subscore of } 2 \text {, } \\
\text { (iii) failed } 2 \text { weeks of oral prednisone } \geq 40 \mathrm{mg} / \text { day (or IV equivalent for at least } 1 \\
\text { week), } \\
\text { (iv) stabilized with } 2 \text { weeks of oral prednisone } \geq 40 \mathrm{mg} / \text { day (or IV equivalent for at } \\
\text { least } 1 \text { week) but the prednisone dose cannot be tapered despite } 3 \text { months of } \\
\text { azathioprine or } 6 \text {-mercaptopurine, or where the use of immunosuppressants is } \\
\text { contraindicated. }\end{array}$ & $\begin{array}{c}\text { Infliximab } \\
\left(\text { Remicade }^{\circledR}\right)\end{array}$ \\
\hline
\end{tabular}

coverage influences the wait time between prescribing the drug and its initiation. Furthermore, drug coverage status may be associated with differences in disease progression and health services utilization. The main aim of this study is to quantitatively evaluate if the type of drug insurance coverage is an independent predictor of the waiting time between prescription and administration of anti-TNF therapy and whether this impacted resource utilization driven by poorly controlled disease.

\section{Methods}

2.1. Patients and Design. A retrospective cohort was recruited from the Mount Sinai Hospital, a large IBD tertiary referral centre. All adult patients ( $\geq 18$ years) with CD or UC who were prescribed anti-TNF therapy from January 1st 2007 to June 30th 2014 were eligible for this study. These individuals were identified by chart review of consecutive patients attending the IBD clinics. During the recruitment period the available anti-TNF agents were infliximab and adalimumab. The EAP coverage criteria for these agents did not change during the study period.

2.2. Data Collection. Demographic characteristics, smoking status, type of drug coverage (private or public), family history of IBD (1st degree), and postal code were collected. Postal code was linked to neighborhood income quintile using the postal code conversion file. Furthermore, we collected clinical characteristics to assess the type, behavior, and activity of IBD. These included Montreal classification [13], steroiddependent or steroid-refractory IBD, age at diagnosis of IBD, duration of the disease up to prescription of biologic therapy, prior use of immunomodulators (azathioprine, 6mercaptopurine, or methotrexate), and previous IBD-related surgery.

The following information was collected about anti-TNF therapy: setting of initiation (outpatient versus inhospital) and time interval between prescription and administration of first dose (days). Additionally, we ascertained whether the anti-TNF therapy was initially funded through a pharmaceutical compassionate drug use program, which provides 
patients drug free of charge while awaiting approval by a private or public insurer.

The primary predictor was type of insurance categorized as private insurance versus public insurance. Those with private drug coverage who applied for supplemental coverage through the publicly funded program were classified as having private insurance. An IBD patient was deemed steroiddependent if they: (1) required two or more corticosteroid courses within a 12-month period; (2) experienced disease relapse when the corticosteroid dose was reduced below $15 \mathrm{mg}$ of prednisone daily or within 6 weeks after stopping corticosteroids. IBD was deemed steroid-refractory when patients did not respond to high-dose oral prednisone (40$60 \mathrm{mg} /$ day or equivalent) within 30 days or the intravenous equivalent dosing for 7 days $[14,15]$. The disease phenotype of IBD was categorized as aggressive in patients with extensive UC (versus left-sided/distal UC); those with stricturing or penetrating $\mathrm{CD}$ (versus inflammatory phenotype); or those who had prior IBD surgery.

We collected the following outcome measures: (1) admission to our hospital with an IBD-related diagnosis after the decision to start biologic therapy and (2) an IBD-related visit to our emergency department (ED) that did not result in admission. Patients at our IBD centre are instructed to go to our ED or IBD-related urgent care whenever possible. Data were collected using a standardized data collection form.

2.3. Statistical Analysis. All analyses were performed with Stata version 14.0 (Statacorp LP, College Station, TX). Categorical data were compared using the chi-square statistic. Ordinal and continuous variables with skewed distribution were compared using Wilcoxon rank sum test.

Subjects who had inpatient initiation anti-TNF were excluded from all analyses pertaining to time from prescription to administration of anti-TNF therapy. These subjects were excluded because the streamlined process for attaining anti-TNF therapy in hospital is substantially more rapid than in the outpatient setting and not dependent on type of insurance coverage. Survival analyses were conducted in which the time-to-event outcome was the time interval from first application for anti-TNF therapy to administration of first dose of anti-TNF. Kaplan-Meier curves were constructed for each payer group and the log-rank test was used to compare unadjusted time-to-event curves.

Unadjusted rates of IBD-related hospitalizations and ED visits were determined by dividing the total number of IBDrelated hospitalization and ER events by the total person-time from prescription of anti-TNF to the end of the study period. Hospitalization and ED rates were compared between those with private and public drug coverage with the chi-square statistics.

2.4. Multivariable Analysis. A multivariable Cox proportional hazard model was conducted to assess whether the type of insurance payer was an independent predictor of the time interval between prescription and administration of anti-TNF agents while adjusting for age, age at diagnosis, sex, neighborhood income quintile, exposure to immunomodulators, history of steroid-dependent or steroid-refractory IBD, aggressiveness of IBD phenotype, and need for supplemental public drug coverage. The robust variance estimator was used to account for clustering by physicians. Poisson regression was performed to assess whether type of insurance payer was associated with hospitalizations and ER visits while adjusting for the same confounders as the Cox regression model.

2.5. Ethics. The study was approved by the research ethics board of the Mount Sinai Hospital of Toronto.

\section{Results}

Two hundred sixty-eight IBD patients (CD, 62\%; UC, 38\%) were prescribed biologic therapy during the study period. All patients in our study cohort eventually received biologic therapy. One hundred ninety-one (71\%) had private drug coverage, while 77 (29\%) had public drug insurance coverage. Infliximab was used more frequently than adalimumab (91\% versus $9 \%)$. Of those with private drug insurance, 30 (16\%) required supplemental public funding through the provincial EAP to assist with copayments. The baseline characteristics of the study population are summarized in Table 2. Sixtythree $(24 \%)$ patients received their first anti-TNF dose while being in hospital, and $40(15 \%)$ patients received their first dose through a compassionate drug use program. Publicly funded individuals were more likely than their privately funded counterparts to be recipients of compassionate use ( $23 \%$ versus $12 \%, P=0.014)$. They were also more likely to have been treated with an immunomodulator at the time of application for anti-TNF therapy (71\% versus 53\%, $P=$ 0.007). There was no difference in neighborhood income quintiles between the two groups.

In addition to comparing demographic and clinical characteristics based on insurance status, we compared these characteristics between patients who received the first dose of biologic therapy within 20 days of prescription (25th percentile) and those who received the first dose more than 60 days after prescription (75th percentile). There were no significant differences in any of the demographic or clinical characteristics analysed.

3.1. Time to First Dose of Anti-TNF Therapy. Figure 1 shows the Kaplan-Meier curves for receiving the first dose of antiTNF therapy after exclusion of individuals who received their first dose in hospital. Patients with public drug insurance experienced greater delay in first dose administration compared to those with private insurance. The median time from prescription to first administration was 19 days longer for those with public drug insurance coverage (53 versus 34 days, $P=0.0216$ ). After exclusion of patients enrolled in a compassionate drug use program, the median delay in starting anti-TNF therapy was 3 weeks longer in the public group (56 versus 35 days, $P=0.002$ ).

The results of univariate and multivariable Cox regression analysis for the association between type of drug insurance coverage and time to first anti-TNF dose are shown in Table 3. After excluding patients who received their first anti-TNF dose while being in hospital, the adjusted hazard ratio (HR) for receiving the first dose of anti-TNF therapy in those with 
TABLE 2: Demographic and clinical characteristics.

\begin{tabular}{|c|c|c|c|c|}
\hline \multirow[b]{2}{*}{ Characteristic } & \multirow{2}{*}{$\begin{array}{l}\text { All patients } \\
(n=268)\end{array}$} & \multicolumn{2}{|c|}{ Type of drug insurance coverage } & \multirow[b]{2}{*}{$P$ value } \\
\hline & & $\begin{array}{c}\text { Public } \\
(n=77) \\
\end{array}$ & $\begin{array}{c}\text { Private } \\
(n=191)\end{array}$ & \\
\hline Age at study inclusion, years. Mean (SD) & $32.5(12.6)$ & $31.8(13.7)$ & $32.8(12.1)$ & 0.548 \\
\hline Age at IBD diagnosis, years. Mean (SD) & $24.2(11.4)$ & $25.4(12.9)$ & $23.7(10.7)$ & 0.316 \\
\hline Disease duration, years. Median (IQR) & $8.5(8.8)$ & $6.9(6.8)$ & $9.1(9.5)$ & 0.247 \\
\hline Male Gender.n (\%) & $136(51)$ & $38(49)$ & $98(51)$ & 0.772 \\
\hline Family history of IBD. $n(\%)$ & $47(18)$ & $13(17)$ & $34(18)$ & 0.858 \\
\hline \multicolumn{5}{|l|}{ Smoking status. $n(\%)$} \\
\hline Never & $215(80)$ & $63(82)$ & $152(80)$ & \multirow[t]{2}{*}{0.677} \\
\hline Former or Current & $53(20)$ & $14(18)$ & $39(20)$ & \\
\hline \multicolumn{5}{|l|}{ Neighborhood income quintile. $n(\%)$} \\
\hline (1) & $29(11)$ & $9(12)$ & $20(10)$ & \multirow{5}{*}{0.880} \\
\hline$(2)$ & $38(14)$ & $13(17)$ & $25(13)$ & \\
\hline (3) & $57(22)$ & $16(21)$ & $41(22)$ & \\
\hline$(4)$ & $56(21)$ & $17(22)$ & $39(22)$ & \\
\hline$(5)$ & $83(32)$ & $21(28)$ & $62(28)$ & \\
\hline Steroid dependent/refractory. $n(\%)$ & $148(55)$ & $49(64)$ & $99(52)$ & 0.079 \\
\hline \multicolumn{5}{|l|}{ Previous/current immunomodulator. $n$ (\%) } \\
\hline Thiopurines & $147(55)$ & $51(66)$ & $96(50)$ & 0.017 \\
\hline Methotrexate & $28(10)$ & $9(12)$ & $19(10)$ & 0.673 \\
\hline Any immunomodulator & $157(59)$ & $55(71)$ & $102(53)$ & 0.007 \\
\hline \multicolumn{5}{|l|}{ IBD type. $n(\%)$} \\
\hline Crohn's disease & $165(62)$ & $48(62)$ & $117(61)$ & \multirow[t]{2}{*}{0.869} \\
\hline Ulcerative colitis & $103(38)$ & $29(38)$ & $74(39)$ & \\
\hline \multicolumn{5}{|l|}{ Montreal classification, Crohn's disease. $n(\%)$} \\
\hline B1 (nonstricturing, nonpenetrating) & $82(50)$ & $30(62)$ & $52(45)$ & \multirow{3}{*}{0.115} \\
\hline B2 (stricturing) & $52(32)$ & $12(25)$ & $40(35)$ & \\
\hline B3 (penetrating) & $30(18)$ & $6(13)$ & $24(21)$ & \\
\hline \multicolumn{5}{|l|}{ Extension of Ulcerative colitis. $n(\%)$} \\
\hline Extensive or Pancolitis & $78(76)$ & $22(76)$ & $56(76)$ & \multirow[t]{2}{*}{0.989} \\
\hline Distal (left-sided/proctitis) & $25(24)$ & $7(24)$ & $18(24)$ & \\
\hline IBD of aggressive behavior. $n(\%)$ & $168(63)$ & $50(65)$ & $127(67)$ & 0.808 \\
\hline Previous surgery.n $(\%)$ & $60(22)$ & $14(18)$ & $46(24)$ & 0.294 \\
\hline Crohn's disease & $54(33)$ & $13(27)$ & $41(35)$ & 0.322 \\
\hline Ulcerative colitis & $6(6)$ & $1(3)$ & $5(7)$ & 0.519 \\
\hline \multicolumn{5}{|l|}{ Biologic agent initiated. $n(\%)$} \\
\hline Infliximab & $243(91)$ & $70(91)$ & $173(91)$ & \multirow[t]{2}{*}{0.932} \\
\hline Adalimumab & $25(9)$ & $7(9)$ & $18(9)$ & \\
\hline Inpatient initiation of anti-TNF. $n(\%)$ & $63(24)$ & $24(31)$ & $39(20)$ & 0.079 \\
\hline Compassionate use program. $n(\%)$ & $40(15)$ & $18(23)$ & $22(12)$ & 0.014 \\
\hline Use of co-pay scheme. $n(\%)$ & $30(11)$ & N/A & $30(16)$ & N/A \\
\hline
\end{tabular}

public versus private coverage was 0.66 (95\% CI: 0.45-0.95, $P=0.026)$.

3.2. Hospitalizations and Emergency Department (ED) Visits. A total of 126 IBD-related admissions and 272 ED visits occurred during the study period. Almost all IBD-related hospitalizations (120 of 126, 95\%) and ED visits (268 of 272, 97\%) occurred after the first dose of biologic therapy was given. Patients with public drug coverage experienced 3fold higher rates of IBD-related hospitalizations than those privately insured (14.9 versus 4.91 hospitalizations per 1000 person-months, $P<0.001)$. Similarly, public drug coverage 


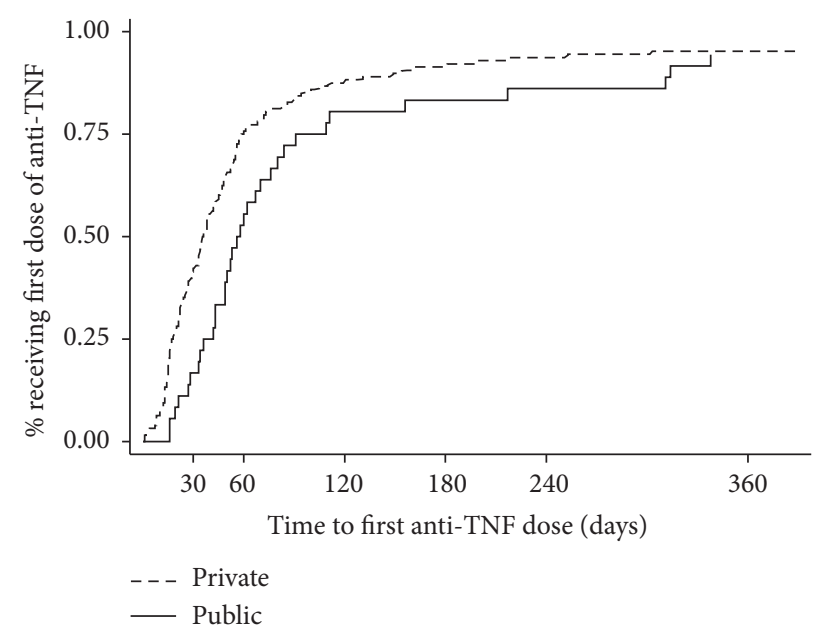

FIgURE 1: Kaplan-Meier curves for time to first dose of anti-TNF therapy stratified type of insurance drug coverage. Publicly funded subjects (solid line) experienced longer times to first anti-TNF dose than privately funded subjects (dashed line).

was associated with a 3-fold higher rate of IBD-related ED visits that did not result in hospitalization (34.6 versus 9.9 ED visits per 1000 person-months, $P<0.001)$ compared with private drug coverage. In sensitivity analyses, those who received anti-TNF in hospital, were recipients of compassionate drug use, or relied on supplemental public funding in addition to private drug insurance were excluded. With these exclusions, hospitalizations and ED visits remained 3fold higher among those with public drug coverage compared with those private coverage (Figure 2).

After adjustment for age, gender, age at diagnosis, neighborhood income quintile, disease duration, disease subtype, history of immunomodulator therapy, history of steroidrefractory or steroid-dependent disease, and aggressive IBD phenotype, publicly funded subjects were more than 2-fold more likely to be hospitalized following the decision to start anti-TNF therapy (Table 4, incidence rate ratio [IRR], 2.30; 95\% CI: 1.19-4.43, $P=0.013)$. Similarly, after controlling for the same confounders, those with public drug coverage were more than twice as likely to require an ED visit that did not lead to hospitalization (Table 5, IRR, 2.42; 95\% CI: 1.44-4.08, $P=0.001)$. Additionally, female gender was an independent predictor of increased IBD-related hospitalization (IRR 2.96, 95\% CI 1.60-5.47) and ED visits (IRR 1.83, 95\% CI 1.033.27).

\section{Discussion}

Access to anti-TNF therapy is fundamental in the provision of high-quality care in IBD. In the Canadian province of Ontario, a government-funded and administered (public) program enables access to these costly medications when an IBD patient does not have sufficient private insurance coverage for prescription drug costs and is unable to pay outof-pocket. Our study has demonstrated that delayed access to critical medical therapies may be driven by the type of drug insurance.

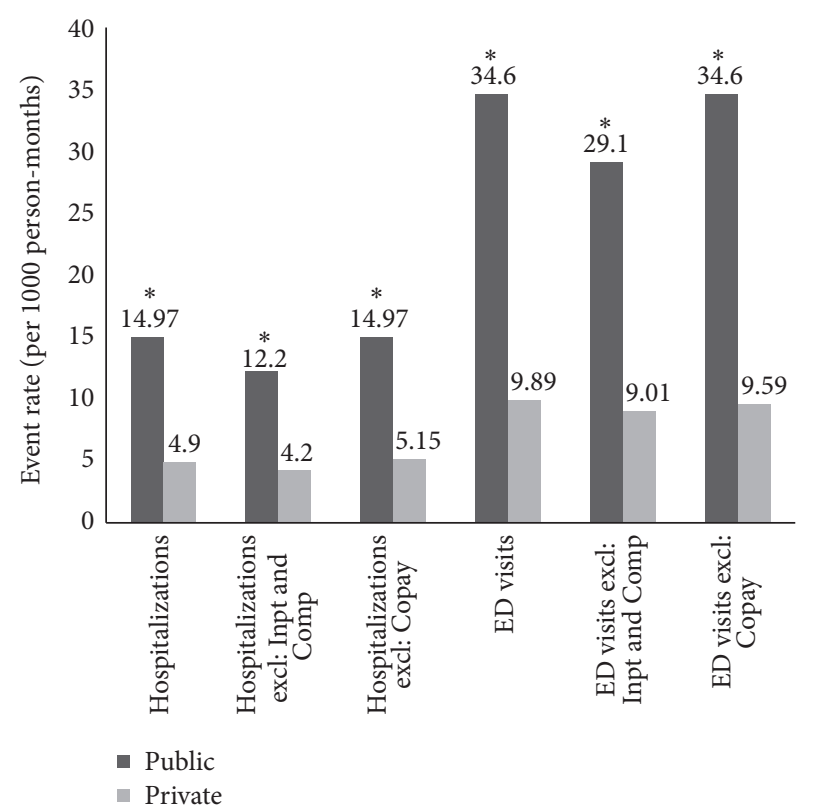

FIGURE 2: Rates of hospitalizations and emergency department visits stratified by public versus private drug insurance coverage. Additional sensitivity analyses are performed in which the following groups were excluded (excl): those who received first anti-TNF dose as inpatients (Inpt) or through a compassionate use program (Comp); those with private drug insurance coverage who received supplemental public funding (Copay). All rate differences between private and public drug coverage were statistically significant $\left({ }^{*} \mathrm{P}<\right.$ $0.001)$.

TABLE 3: Results of the Cox regression analysis of type of drug insurance coverage and time to first anti-TNF dose.

\begin{tabular}{lcc}
\hline Characteristic & Hazard ratio & $95 \%$ CI \\
\hline Public drug coverage & 0.67 & $0.45-0.95$ \\
Age & 1.00 & $0.98-1.03$ \\
Age at IBD diagnosis & 1.00 & $0.98-1.03$ \\
Female gender & 1.10 & $0.78-1.56$ \\
Crohn's disease & 1.46 & $1.00-2.12$ \\
Immunomodulator use & 1.16 & $0.82-1.65$ \\
Steroid dependent or refractory disease & 1.02 & $0.74-1.41$ \\
IBD of aggressive behaviour & 0.81 & $0.55-1.18$ \\
Copay scheme use & 0.74 & $0.37-1.48$ \\
\hline
\end{tabular}

In our cohort, nearly a third of patients who require anti-TNF therapy required assistance through the provincial government's exceptional access program (EAP). In patients with private drug coverage, nearly a third required additional payment support in the form of compassionate access from the drug company or copay assistance. Furthermore, the lack of supplementary drug coverage was an independent predictor for increased utilization of nonroutine healthcare services. In our cohort, patients without private drug coverage were greater than 2-fold more likely to require IBD-related hospitalization and ED visits, after adjusting for demographic and clinical cofounders, including socioeconomic status. Our findings that most hospitalizations and ED visits occurred 
TABLE 4: Poisson regression model for IBD-related admissions.

\begin{tabular}{lcr}
\hline Characteristic & Unadjusted IRR (95\% CI) & Adjusted IRR (95\% CI) \\
\hline Type of drug coverage & ref & ref \\
$\quad$ Private & $2.32(1.27-4.25)$ & $2.30(1.19-4.43)$ \\
$\quad$ Public & $0.99(0.97-1.02)$ & $1.00(0.97-1.03)$ \\
Age & $0.99(0.97-1.02)$ & $0.99(0.96-1.03)$ \\
Age at IBD diagnosis & ref & ref \\
Sex & $2.97(1.63-5.42)$ & $2.96(1.60-5.47)$ \\
$\quad$ Male & ref & ref \\
$\quad$ Female & $0.77(0.39-1.52)$ & $0.75(0.37-1.53)$ \\
IBD subtype & $1.52(0.79-2.94)$ & $1.28(0.67-2.46)$ \\
$\quad$ Crohn's disease & $1.68(0.92-3.06)$ & $1.76(1.01-3.05)$ \\
$\quad$ Ulcerative colitis & $0.86(0.45-1.63)$ & $1.15(0.60-2.20)$ \\
Immunomodulator use & & ref \\
Steroid dependent or refractory & ref & $1.21(0.53-2.75)$ \\
Aggressive IBD phenotype & $1.10(0.43-2.81)$ & $0.77(0.32-1.84)$ \\
Median neighborhood income & $0.62(0.22-1.74)$ & $0.46(0.17-1.26)$ \\
1st quintile & $0.35(0.12-1.01)$ & $0.96(0.43-2.12)$ \\
2nd quintile & $0.83(0.33-2.12)$ & \\
3rd quintile & & \\
4th quintile & & \\
5th quintile & & \\
\hline
\end{tabular}

TABLE 5: Poisson regression model for IBD-related ED visits.

\begin{tabular}{lcr}
\hline Characteristic & Unadjusted IRR (95\% CI) & Adjusted IRR (95\% CI) \\
\hline Type of drug coverage & ref & ref \\
$\quad$ Private & $2.67(1.57-4.55)$ & $2.42(1.43-4.08)$ \\
$\quad$ Public & $0.99(0.97-1.01)$ & $0.99(0.97-1.01)$ \\
Age & $0.99(0.96-1.02)$ & $0.99(0.96-1.03)$ \\
Age at IBD diagnosis & & ref \\
Sex & $1.87(1.07-3.26)$ & $1.83(1.03-3.27)$ \\
$\quad$ Male & & ref \\
Female & ref & $0.69(0.35-1.36)$ \\
IBD subtype & $0.63(0.32-1.24)$ & $1.87(1.07-3.27)$ \\
$\quad$ Crohn's disease & $2.30(1.29-4.09)$ & $1.48(0.90-2.45)$ \\
$\quad$ Ulcerative colitis & $1.59(0.93-2.70)$ & $0.59(0.20-1.80)$ \\
Immunomodulator use & $0.75(0.43-1.30)$ & ref \\
Steroid dependent or refractory & ref & $0.76(0.35-1.65)$ \\
Aggressive IBD phenotype & $0.75(0.30-1.85)$ & $0.64(0.30-1.38)$ \\
Median neighborhood income & $0.57(0.24-1.35)$ & $0.43(0.17-1.13)$ \\
1st quintile & $0.35(0.12-1.00)$ & $0.88(0.40-1.94)$ \\
2nd quintile & $0.81(0.35-1.90)$ & \\
3rd quintile & & \\
4th quintile & & \\
5th quintile & & \\
\hline
\end{tabular}

after the first dose of biologics was administered are worrisome. It suggests that perhaps there may be a durable impact of delayed access to biologics beyond drug initiation.

These findings are disconcerting in a system where all medically necessary health services are covered by a single payer but where prescription drug insurance coverage is not universally covered. In this system, reliance on public insurance may therefore introduce disparities in quality of care. Barriers to access may arise when the administrative review process frequently takes longer through the EAP program, often requiring multiple cycles of correspondence between the assessor and physician. 
Physicians are able to partly compensate for delays in access to anti-TNF therapy through compassionate use programs funded by industry which essentially provide biologics free of charge for individuals who are unable to pay. Healthcare providers and patient advocacy groups should, therefore, lobby industry to sustain and expand compassionate use programs to reduce delays in access to biologics. Moreover, the recent introduction of a lower priced biosimilar of infliximab, which has been added to the Ontario Drug Formulary as a limited use (LU) drug product, will likely enhance access to anti-TNF therapy for those relying on public coverage. In Ontario, physicians are able to prescribe limited use drugs for specific clinical indications without having to navigate through the more complicated EAP review process.

As far as we are aware, to date there are no published studies assessing whether drug coverage is associated with delayed access to biologic therapy, adverse clinical outcomes, or increased utilization of healthcare studies. This holds true for IBD and other inflammatory conditions that require biologic therapy, such as rheumatoid arthritis, psoriasis, and psoriatic arthritis. This is the first study assessing these concerns in a universal healthcare system.

A major limitation of our study is that subjects were from a single tertiary centre, thus reducing our findings' generalizability. As a referral centre, we manage a higher proportion of complex IBD patients compared to most community practices and our patient population has high rate of biologic therapy use. The high volumes of patients on anti-TNF therapy at our institution reflect our experience in facilitating access to these drugs, especially for those requiring public coverage. Thus, insurance-based disparities in our study may underestimate the barriers in access experienced by community gastroenterology practices. Moreover, our findings reflect access patterns in Ontario but may not be generalizable to other provinces. Because Ontario accounts for more than a third of the Canadian population, issues surrounding medication access in this province certainly have national impact.

Furthermore, in assessing healthcare utilization, we only captured IBD-related admissions and ED visits at our institution. This likely leads to underestimation of rates of hospitalization and ED visits as patients may have received care at other centres in the Greater Toronto Area. While we attempted to adjust for aggressive IBD phenotype and other indicators of disease severity, there may have been residual confounding that partially explains differences in hospitalizations and ED visits between payer types. An additional limitation is that we did not collect data on whether continuation of biologic therapy in the follow-up period differed by payer type.

In conclusion, this study provides evidence that the type of drug coverage is an independent predictor of access to biologic therapy in IBD patients from Ontario. Cost analyses are needed to assess the economic impact of delays to antiTNF therapy. Moreover, these insurance-based disparities likely extend beyond IBD to other conditions that require use of costly biologic therapies, including a myriad of rheumatologic conditions. As physicians and health policy makers, we must contemplate whether Canada can be truly considered to have a universal healthcare system when prompt access to critical medications relies on private drug insurance coverage.

\section{Disclosure}

Neither Janssen nor the FLIBD had a role in the design or conduct of the study, the interpretation of results, or the development of this manuscript.

\section{Competing Interests}

K. Croitoru received educational grants from Janssen, Abbvie, and Takeda and has served on advisory boards for Abbvie and Takeda. A. H. Steinhart received research grants from Abbvie, Amgen, Pfizer, and Millennium and speaking honoraria from Abbvie, Janssen, Takeda, and Shire; he has served on advisory boards for Abbvie, Actavis, Janssen, Takeda, Pharmascience, and Shire. M. S. Silverberg received research support and consulting fees from Janssen, Abbvie, Takeda, and Prometheus.

\section{Authors' Contributions}

Geoffrey C. Nguyen and Justina J. Sam conceived the study. Geoffrey C. Nguyen obtained funding and with Roberto Candia and Amir Rumman drafted the manuscript. Roberto Candia, Amir Rumman, and Geoffrey C. Nguyen participated in study design and conducted analyses. Justina J. Sam, Amir Rumman, Kenneth Croitoru, Mark S. Silverberg, and A. Hillary Steinhart contributed to development of the study protocol, study recruitment, and data collection. All coauthors critically reviewed and approved the manuscript.

\section{Acknowledgments}

The study was funded by an academic peer-reviewed grant through the Future Leaders in IBD (FLIBD) program sponsored by Janssen.

\section{References}

[1] I. Ordás, L. Eckmann, M. Talamini, D. C. Baumgart, and W. J. Sandborn, "Ulcerative colitis," The Lancet, vol. 380, no. 9853, pp. 1606-1619, 2012.

[2] D. C. Baumgart and W. J. Sandborn, "Crohn's disease," The Lancet, vol. 380, no. 9853, pp. 1590-1605, 2012.

[3] A. D. Frolkis, J. Dykeman, M. E. Negrón et al., "Risk of surgery for inflammatory bowel diseases has decreased over time: a systematic review and meta-analysis of populationbased studies," Gastroenterology, vol. 145, no. 5, pp. 996-1006, 2013.

[4] S. Danese, G. Fiorino, L. Peyrin-Biroulet et al., "Biological agents for moderately to severely active ulcerative colitis: a systematic review and network meta-analysis," Annals of Internal Medicine, vol. 160, no. 10, pp. 704-711, 2014.

[5] D. C. Baumgart and W. J. Sandborn, "Inflammatory bowel disease: clinical aspects and established and evolving therapies," Lancet, vol. 369, no. 9573, pp. 1641-1657, 2007. 
[6] S. T. Rietdijk and G. R. D’Haens, "Recent developments in the treatment of inflammatory bowel disease," Journal of Digestive Diseases, vol. 14, no. 6, pp. 282-287, 2013.

[7] A. C. Ford, W. J. Sandborn, K. J. Khan, S. B. Hanauer, N. J. Talley, and P. Moayyedi, "Efficacy of biological therapies in inflammatory bowel disease: systematic review and metaanalysis," The American Journal of Gastroenterology, vol. 106, no. 4, pp. 644-659, 2011.

[8] G. D’Haens, F. Baert, G. van Assche et al., "Early combined immunosuppression or conventional management in patients with newly diagnosed Crohn's disease: an open randomised trial," The Lancet, vol. 371, no. 9613, pp. 660-667, 2008.

[9] S. M. Devlin and R. Panaccione, "Evolving inflammatory bowel disease treatment paradigms: top-down versus step-up," Medical Clinics of North America, vol. 94, no. 1, pp. 1-18, 2010.

[10] B. G. Feagan, W. J. Sandborn, A. Lazar et al., "Adalimumab therapy is associated with reduced risk of hospitalization in patients with ulcerative colitis," Gastroenterology, vol. 146, no. 1, pp. 110.e3-118.e3, 2014.

[11] W. J. Sandborn, P. Rutgeerts, B. G. Feagan et al., "Colectomy rate comparison after treatment of ulcerative colitis with placebo or infliximab," Gastroenterology, vol. 137, no. 4, pp. 1250-1260, 2009.

[12] J. P. Leombruno, G. C. Nguyen, P. Grootendorst, D. Juurlink, and T. Einarson, "Hospitalization and surgical rates in patients with Crohn's disease treated with infliximab: a matched analysis," Pharmacoepidemiology and Drug Safety, vol. 20, no. 8, pp. 838-848, 2011.

[13] M. S. Silverberg, J. Satsangi, T. Ahmad et al., “Toward an integrated clinical, molecular and serological classification of inflammatory bowel disease: report of a Working Party of the 2005 Montreal World Congress of Gastroenterology," Canadian Journal of Gastroenterology, vol. 19, Supplement A, pp. 5A-36A, 2005.

[14] C. Mowat, A. Cole, A. Windsor et al., "Guidelines for the management of inflammatory bowel disease in adults," Gut, vol. 60, no. 5, pp. 571-607, 2011.

[15] E. F. Stange, S. P. L. Travis, S. Vermeire et al., "European evidence-based Consensus on the diagnosis and management of ulcerative colitis: definitions and diagnosis," Journal of Crohn's and Colitis, vol. 2, no. 1, pp. 1-23, 2008. 


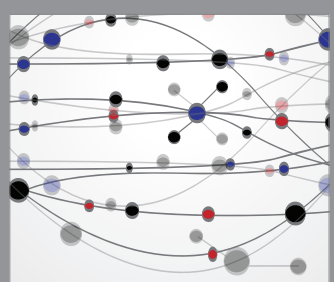

The Scientific World Journal
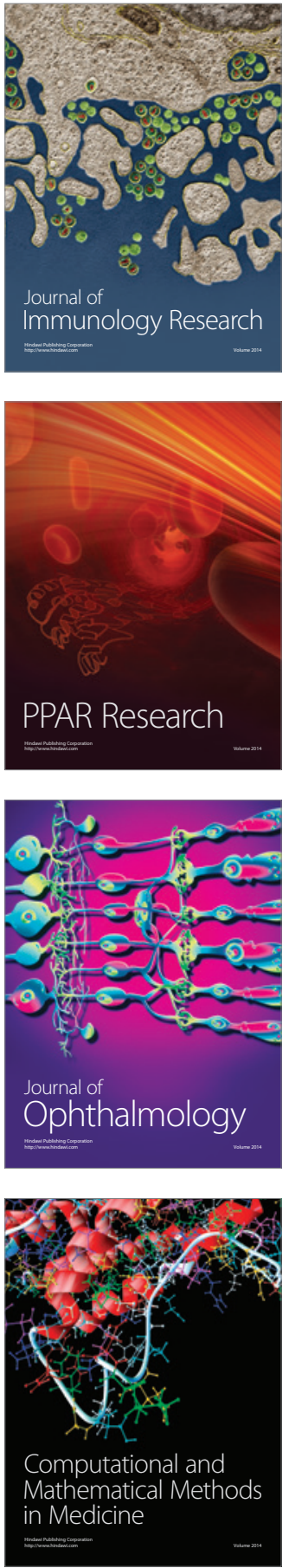

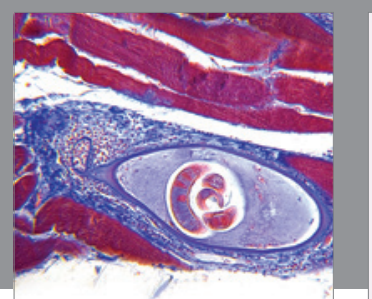

Gastroenterology Research and Practice
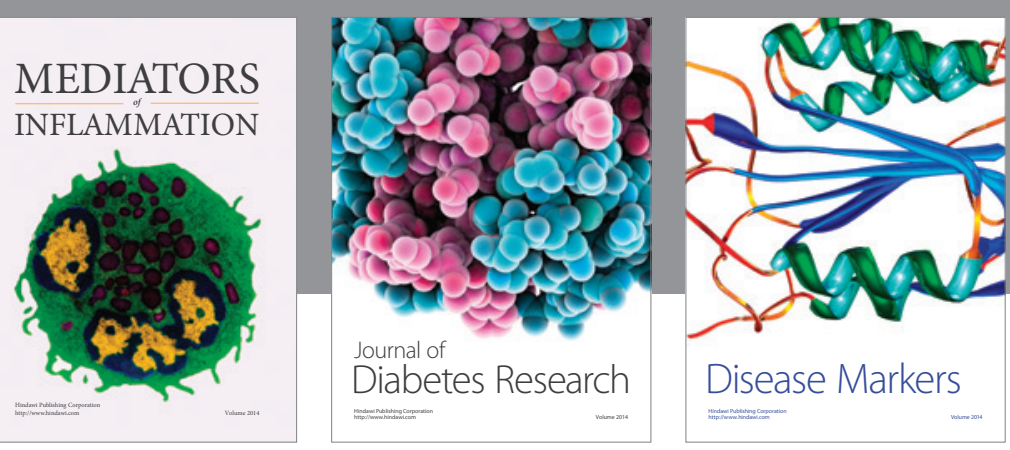

Disease Markers

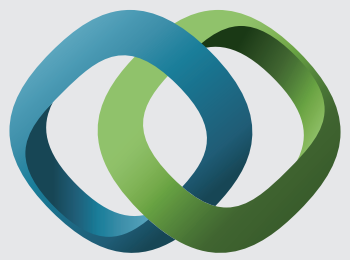

\section{Hindawi}

Submit your manuscripts at

https://www.hindawi.com
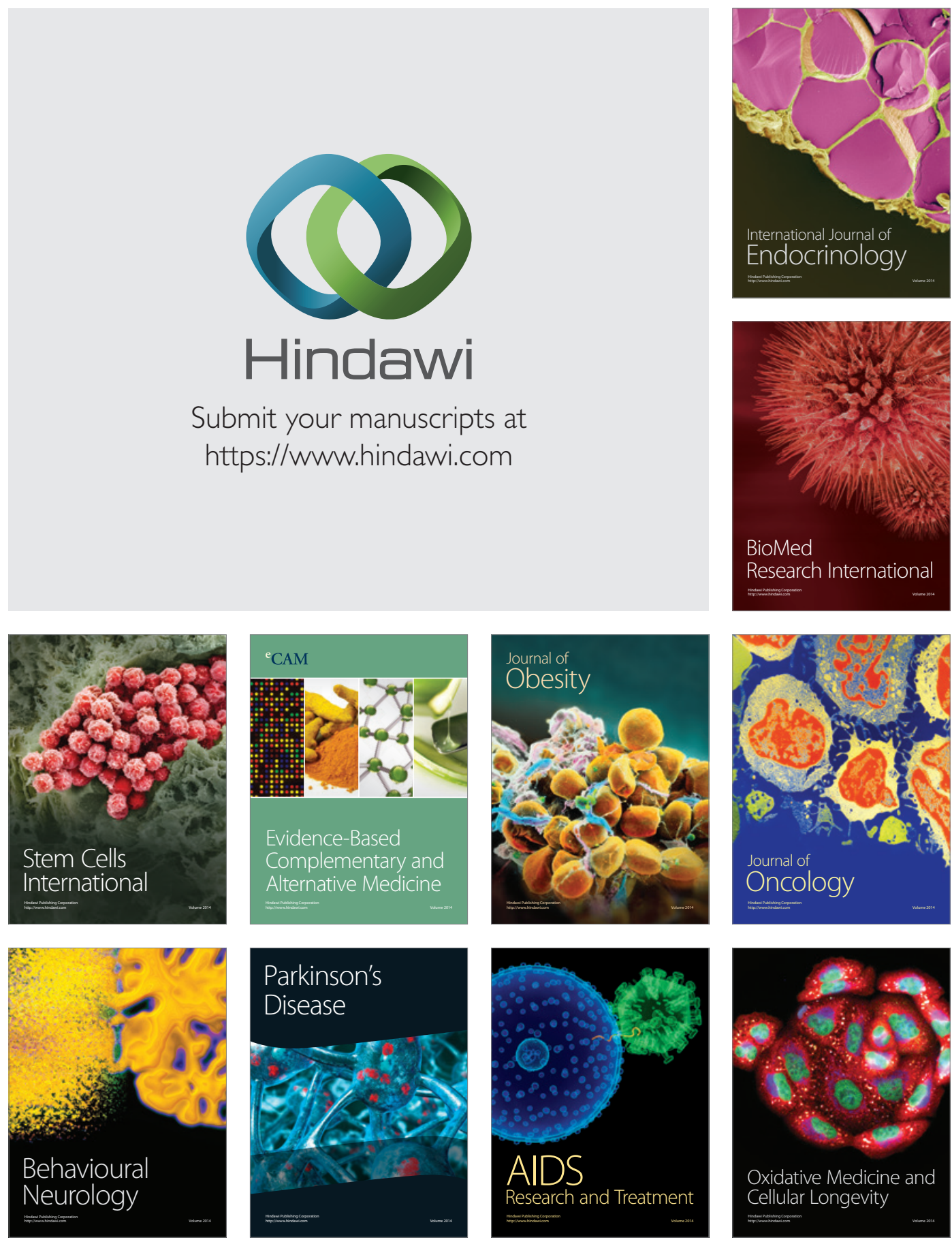